\title{
Article \\ A Survey Study on U.S. College Students' Learning Experience in COVID-19
}

\author{
Jiahua Zhou ${ }^{1}$ and Qiping Zhang ${ }^{2, *}$ \\ 1 Jericho Senior High School, Jericho, NY 11753, USA; jiahua-allen.zhou@jerichoapps.org \\ 2 Palmer School of Library and Information Science, Long Island University, Brookville, OH 11548, USA \\ * Correspondence: qiping.zhang@liu.edu
}

Citation: Zhou, J.; Zhang, Q. A Survey Study on U.S. College Students' Learning Experience in COVID-19. Educ. Sci. 2021, 11, 248. https://doi.org/10.3390/

educsci11050248

Academic Editor: Kelum Gamage

Received: 2 April 2021

Accepted: 13 May 2021

Published: 20 May 2021

Publisher's Note: MDPI stays neutral with regard to jurisdictional claims in published maps and institutional affiliations.

Copyright: (c) 2021 by the authors. Licensee MDPI, Basel, Switzerland. This article is an open access article distributed under the terms and conditions of the Creative Commons Attribution (CC BY) license (https:// creativecommons.org/licenses/by/ $4.0 /)$.

\begin{abstract}
COVID-19 affected various aspects of our life. Many college students were forced to take courses remotely. It was not clear how they adapted to this new environment and how their mental health was affected. The objective of this study is to understand college students' learning experience one year after the outbreak of COVID-19. An online survey was developed to investigate students' overall learning process, mental health, perception of the learning community and student support. Sixty-two college students in the U.S. were recruited through an online survey platform. Findings of this study revealed: (1) improved mental health of college students compared to the beginning of the pandemic; (2) an overall positive learning experience and perceived belongingness to their learning community, as well as high satisfaction with the student support; (3) the major hindrance in the online learning environment was the lack of interactions with teachers and classmates; (4) a relationship between family income and perception of the learning community was discovered, and the students from low-income families were found to feel more belonging to the learning community; (5) hybrid was the optimum learning mode during COVID-19; (6) on-campus students perceived more student support than off-campus students. These findings provided a guideline for future research to further explore, and improve, the online learning environment.
\end{abstract}

Keywords: college student; learning experience; COVID-19; survey; anxiety; depression; learning mode

\section{Introduction}

The novel coronavirus SARS-CoV-2, known as COVID-19, is a disease that outburst from Hubei Province of China to the world at the beginning of 2020. The World Health Organization (WHO) declared a global health emergency for containment of this disease on 30 January 2020 [1]. By 23 March 2020, there were approximately 353,000 positive cases and more than 15,000 deaths globally [2]. According to [3], approximately 138 countries closed up their schools by March, which instantaneously affected about $80 \%$ of students worldwide.

As a result, alternatives to onsite learning were necessary [4]. In the U.S., remote online learning was initially a major alternative since March 2020. With the improvement of the COVID-19 situation and the opening of college campuses to students since the winter semester 2020, three alternative learning modes emerged: in-person, hybrid, and remote.

In-person learning allows the richest teacher-student and student-student interactions, but the uncertainty of COVID-19 spreading and insufficient social distancing in classrooms may cause certain levels of anxiety and depression to students. Remote learning is considered the safest mode, but the lack of in-person interaction between teacher-student and student-student may lead to loneliness, even anxiety, or depression. Hybrid, as a tradeoff between safety concern and in-person interaction, might provide the best learning mode for college students, but most colleges and universities were not able to support it due to insufficient on-campus resources. 
In fact, due to the different sanitation conditions of the college, the combinations of learning modes and places were complicated. For example, some private colleges allowed students to stay on campus to learn in-person, but students were not allowed to go outside the campus once they were admitted to the campus. They needed to run weekly COVID-19 testing in order to stay on campus. Some colleges, such as Harvard, allowed students to stay on-campus but study remotely. Students also need to be tested weekly to ensure the safety of the dorm. Some public colleges, such as The City University of New York (CUNY), only allowed students to study remotely. The campus was completely closed.

To react to remote learning, some students chose to stay on campus, while others chose to live off-campus with friends. When students stay on campus, they could still have some levels of in-person interactions with peers outside the classroom. When students live off-campus with friends, they avoided an intense dorm environment and thus, reduced the risk to be affected by COVID-19.

The complicated learning system was indeed a challenge for both students and faculty, since neither of them was familiarized with remote learning. It had strong effects on student's learning experience and mental health: whether a student chose to stay oncampus or learning from home, many of them had experienced the different extent of mental health problems. For example, college life requires student interaction, but the social distancing during COVID-19 limits the chance of getting face-to-face contact, which causes anxiety for students. While both students and faculty learned to adapt themselves for the changes during COVID-19, it is crucial to investigate college students' learning experience one year after the outbreak of COVID-19. Will students still demonstrate similar levels of depression and anxiety at the beginning of COVID-19 [5,6]?

The objective of this study was to discover college students' learning experience and, in particular, perception of the learning community, satisfaction level, hindrance that they had encountered, and mental health, including their anxiety and depression level, one year after the outburst of COVID-19.

The rest of the paper is organized in the following way. In the literature review, related research on remote learning and mental health issues are reviewed. In the method, research questions, participant information, procedure, survey design, and data analysis plan are explained. In the results, it starts with the results of demographic information and reliability analysis, followed by descriptive analyses of survey responses corresponding to five research questions, and inferential analyses of impacts of students' grade (freshman, sophomore, junior, senior), gender, ethnicity, family income, learning mode, and learning location on their learning experience and mental health. In the discussion, five themes out of our results were elaborated. Finally, the conclusion section summarized major findings, limitation of the study, and future research.

\section{Literature Review}

In this section, academic coping strategy to COVID-19 was first reviewed, followed by introduction of remote learning, and previous questionnaires related to learning experience. The section ended with a review of research on health issues related to COVID-19.

\subsection{Academic Responses to COVID-19}

According to [7], all states in the United States were well prepared for implementing remote learning by 31 March 2020. The overall goal was to continue the education in the lock down period. Although the purpose was the same, the different universities developed different coping strategies for remote learning based on their condition. For example, when the shortage of online learning equipment (iPad, laptop, desktop) appeared, non-digital alternatives (such as mailing print textbooks or handout) were offered. On the other hand, the adjustment of curriculums and the grading policies were needed as well. The equality of special populations, such as ENL (English as a New Language) and handicapped students, was another challenge that universities faced. While continuing on the education through online learning mode, it is more important for the state education 
agencies to acknowledge the difficulties of students in this period, and it is critical to pay close attention to student support that helps them to get away from stresses [7].

According to [8], the Chinese Ministry of Education implemented a policy of suspending classes without stopping learning in response to the school's closures during COVID-19. They encountered many obstacles in delivering remote learning. For example, the heavy use of the internet caused regional network crashes. In addressing the problems of the inexperienced teachers and the lack of the online learning resources, the Chinese Ministry of Education integrated national resources (such as ordered the major communications companies to maintain a stable internet connection), trained the teachers online, and created platforms for students and teachers to share their online learning/teaching methods and experiences. Because of the unequal development of infrastructure in many provinces, localized strategies for remote learning were also developed based on their local conditions. In particular, the mental and physical wellness of students was paid special attention to in preparing for reopening schools after a pandemic [8].

\subsection{Remote Learning}

Remote learning, known as e-learning, online learning, or distant learning, was an innovative learning method being introduced in the twentieth century. One great example is the massive open online courses (MOOCs). It is an online platform that provides regular courses which can be accessed from anywhere in the world. Compared to the ordinary inperson classes, some students favor its self-paced learning style that promotes their learning motivation and comprehensiveness. However, some students who were less familiar with using computers and the internet to take courses appear to be uncomfortable and reject the use of e-learning because they are afraid that it would decrease their course performance [9]. During the pandemic period, when college students were forced to take their courses remotely, they reported both technology difficulties and resources challenges $[5,6]$.

There are two major learning modes in remote learning: hybrid and online. In contrast to online learning, where students take courses completely online, hybrid remote learning refers to a combination of in-person and online class meetings. Through a semester, students are required to take a certain number of in-person classes while taking the rest of classes online. Hybrid mode allows students to have in-person interactions with peers and the instructors, and also saves students travel and commuting time when they take classes online, thus hybrid is considered as a good choice for remote learning.

\subsection{Learning Experience Measurement}

In the following, various survey instruments were reviewed regarding four facets of learning experiences: online learning experience, satisfaction, motivation, and learning strategy, and emotion.

\subsubsection{Measure of Learning Experience in Online Learning (OLEQ, DLQ)}

Online Learning Experience Questionnaire (OLEQ) was developed for measuring students' experience of online learning based on an evaluation framework. It consists of 27 items, exploring 6 aspects of the online learning experience: (1) access of information and learning materials, (2) flexibility and convenience, (3) opportunity for interacting with peers, (4) opportunity for interacting with teachers, (5) the value of supplementary face-toface resource sessions, and (6) overall satisfaction with online learning. The participants were asked to respond to this survey with a 4-point-likert scale that ranged from 'strongly disagree' to 'strongly agree' [10].

The COVID-19 Distance Learning Questionnaire (DLQ) was developed to estimate the effectiveness of remote learning in Ukraine. It both evaluates the negative and positive aspects of distance learning [11]. 


\subsubsection{Measure of Satisfaction in Learning Experience (CEQ, CEQS)}

Because the Performance indicators (PIs) only focus on the learning outcome, ignoring the learning and teaching process, the Australian researchers developed Course Experience Questionnaire (CEQ) to measure the teaching quality and perception of the learning quality of college students. It uses a 5-point Likert-scale. The initial 80 items were shortened into 57 items after ambiguous items were filtered. It measures five aspects of course experiences: (1) good teaching; (2) clear goals and standards; (3) appropriate workload; (4) appropriate assessment, and (5) emphasis on independence [12].

A shortened version of CEQ developed in [13] keeps 25 items and consists of six major dimensions. It filtered out the dimension of "emphasis on independence" and added two outcome constructs: generic skills ( 6 items) and satisfaction ( 1 item). The four antecedent constructs kept the same as the CEQ version in [12]: good teaching (6 items), clear goals and standards ( 5 items), appropriate workload (4 items), appropriate assessment ( 3 items). Through examination, the researchers found that there was a strong impact of good teaching and clear goals on students' generic skills and satisfaction, while appropriate workload and appropriate assessment did not have a strong impact on generic skills and satisfaction [14].

Course Experience Quality and Satisfaction Model (CEQS) [14] is used to evaluate student's general learning efficiency and satisfaction level of their learning experiences. It consisted of three major parts: demographic information, CEQ (25 items), and global student satisfaction measurements (4 items).

\subsubsection{Measure of Motivation and Learning Strategies (MSLQ)}

Motivated Strategies for Learning Questionnaire (MSLQ) is a Likert-scaled questionnaire developed to evaluate college students' motivational orientations and learning strategies. It consists of 31 items that access student's motivation and 50 items for accessing their learning strategies. More specifically, it includes the measurement of goal orientation, task value, control beliefs about learning, self-efficiency, and test anxiety. The scale is reliable and demonstrates valid results [15-17].

\subsubsection{Measure of Emotions in Learning Experience (AEQ)}

Achievement Emotions Questionnaire (AEQ) aims to evaluate student's achievement emotions. It uses a 5-point Likert scale and consists of three major categories: Class-related emotions scales ( 80 items), Learning-related emotions scales (75 items), and Test Emotions scales (77 items). Each category includes 8 emotions: enjoyment, hope, pride, relief, anger, anxiety, shame, hopelessness, and boredom [18].

\subsection{Health Issues Related to COVID-19}

Although the campus closure might be good for preventing the spread of COVID-19 virus, a long-term closure might cause both physical and mental health problems. In fact, the anxiety level was found to be higher during COVID-19 than before [19]. Obesity, which is usually caused by unhealthy diets and the lack of physical activities, was also a product of long-term closure. Even worse, the weight gain might make people more anxious and aggravate their mental health [20].

The social media exposure (SME) was a possible source of anxiety. A survey was conducted in China to discover the relationship between SME and the anxiety level [5]. People usually felt bored during the closure, so they might frequently visit social media. Based on the data collected from Jan to Feb 2020, about half of the people were at different levels of anxiety, during COVID-19, in Wuhan. Through the analysis and comparison between the SME and the results from a depression scale (WHO-5: Well-Being Index) and an anxiety scale (GAD-7: Generalized Anxiety Disorder Scale), the researchers found that the people with anxiety were more frequently using social media than people with no symptoms or slight symptoms, which indicated a direct relationship between the SME and 
high level of anxiety [5]. The anxiety might be caused by the mass amount of negative news and pessimistic discussion about COVID-19 that were glutting the social media [21].

Studies from other researchers also suggested that the people's anxiety level could relate to their locations [22,23] and the wellness of their relatives [22]. For example, people in China who lived in cities were found to be less anxious than people who lived in rural areas due to the better sanitization measures and medical resources in cities than in rural areas [22]. People who lived in countries with weak medical facilities were more likely to be involved with mental problems [23]. On the other hand, people who have relatives infected with Coronavirus had higher levels of anxiety than people with relatives who were safe and healthy [22].

The wellness of people could also vary by their education level and coping strategy [6]. For instance, highly educated people were less likely to be prone to health problems during COVID-19, and good coping strategies could effectively prevent people from getting infections.

In order to cope with these problems, governments developed intervention strategies to promote wellness, such as creating videos and webinars to educate quarantine information and skills [21], building an online platform for people to share their wellness approaches [19], and spreading of financial assistance [24].

In summary, the design of our survey was based on four existing scales from above. It turned out that the shortened version of CEQ, developed in [13], was most frequently used for measuring teaching quality and student's satisfaction. In the same way, the OLEQ, developed in [10], was specifically to measure the learning experience in online learning conditions. Two scales (GAD-7 and WHO-5) measuring mental health conditions during COVID-19 by [5] would be used by our study to measure college students' anxiety and depression.

\section{Method}

\subsection{Research Questions}

This study addressed following five research questions:

RQ1: What was college students' overall learning process during COVID-19?

RQ2: What was the impact of COVID-19 on college students' mental health?

RQ3: What was college students' perception of the learning community during COVID-19?

RQ4: What was college students' perception of student support during COVID-19?

RQ5: What were the benefits and barriers of taking a course remotely in COVID-19?

\subsection{Participant}

Upon xxx IRB approval, a total of 62 participants were recruited online from Amazon Mechanical Turk (Mturk), a virtual crowdsourcing marketplace in January 2021. The screening criteria was any college student currently studying in the U.S., and each participant obtained $\$ 1$ from Mturk after their completion was verified.

Initially, we planned to recruit participants from a college campus. However, due to COVID-19, it was difficult to recruit enough participants on campus. We then decided to use Mturk to disseminate the survey to recruit participants.

\subsection{Procedure}

First, an online survey was developed in Google Form, an online survey platform.

Second, an online job-Human Intelligence Task (HIT) for completing the above survey was created at Amazon Mechanical Turk in the first week of January 2021. Participants were given up to $30 \mathrm{~min}$ to complete it.

Third, a $\$ 1$ participation fee was awarded if the Mturk ID was matched between the one participant offered on Google Form and the one Mturk provided on the completion list. When participants filled out the survey repeatedly, the most recent response was taken, and all previous ones were discarded. 
Fourth, the HIT of survey completion was reposted five days after the first round of dissemination. In the first round, 42 valid responses were received in three days, but the number of participants did not increase in the following days. By reposting the same HIT in Mturk, the survey job appeared on the top list. It brought an additional 32 participants. It was interesting to note that quite a few responses (12) in the second round were the same participants in the first round. Thus, a saturation in this participant pool was probably reached, and a total of 62 valid responses were obtained. Though we would have liked to receive more responses, we decided to stop the recruitment process three days after our second round of dissemination.

\subsection{Survey Design}

In this study, we investigated the learning experience of college students a year after the starting of school closure. The College Student Learning Experience Survey was developed based on Online Learning Experience Questionnaire [10], Well-Being Index (WHO-5) [5], Generalized Anxiety Disorder scale (GAD-7) [6], and the Course Experience Questionnaire (CEQ) [13].

The questionnaire consists of 42 items, including 6 items related to demographic information (age, gender, ethnicity, family income, learning mode, learning location), and 36 items of five major constructs corresponding to our five research questions (RQ). Table 1 showed the detailed mapping of $R Q$, survey constructs, survey questions and survey sources.

Table 1. Mapping of RQ, Survey Constructs, Survey Questions and Survey Sources.

\begin{tabular}{|c|c|c|c|}
\hline RQ & Construct & Question & Source \\
\hline & $\begin{array}{l}\text { Demographic } \\
\text { information }\end{array}$ & $\begin{array}{l}\text { 1. What is your current year in college? } \\
\text { 2. What is your gender? } \\
\text { 3. What is your family annual income? } \\
\text { 4. What is your ethnicity? } \\
\text { 5. What was your choice of learning mode? } \\
\text { 6. If you were a remote/hybrid, where did you take your class? }\end{array}$ & SurveyMonkey ${ }^{\circledR}$ \\
\hline RQ1 & $\begin{array}{l}\text { Overall Learning } \\
\text { Process }\end{array}$ & $\begin{array}{l}\text { Please indicate your agreement degree with the following statements. } \\
\text { (5-likert scale) } \\
\text { I was encouraged to take responsibility for my own learning } \\
\text { I was able to work through the subject material at my own pace } \\
\text { It was easy to navigate the subject learning material } \\
\text { The face-to-face resource sessions were valuable when supplemented with } \\
\text { online learning } \\
\text { Electronic communication with the subject lecturer was useful }\end{array}$ & [10] \\
\hline RQ2 & Mental health & $\begin{array}{l}\text { How often have you been bothered by the following feelings? }(1=\text { not at all, } \\
2=\text { several days, } 3=\text { more than half of the days, } 4=\text { nearly everyday }) \\
\text { Feeling nervous, anxious, or on edge. Not being able to stop or control } \\
\text { worrying. Being so restless that it's hard to sit still. } \\
\text { Becoming easily annoyed or irritable. } \\
\text { Feeling afraid as if something awful might happen. } \\
\text { Worrying too much about different things. } \\
\text { Trouble relaxing. } \\
\text { How often do you have the following positive feelings? }(1=\text { no time, } 2=\text { some of } \\
\text { the time, } 3=\text { less than half of the time, } 4=\text { more than half of the time, } 5=\text { most of } \\
\text { the time, } 6=\text { all the time) } \\
\text { I have felt calm and relaxed. } \\
\text { I have felt active and vigorous. } \\
\text { I woke up feeling fresh and rested. } \\
\text { I have felt cheerful in good spirits. } \\
\text { My daily life has been filled with things that interest me. }\end{array}$ & {$[5,6]$} \\
\hline
\end{tabular}


Table 1. Cont.

\begin{tabular}{|c|c|c|c|}
\hline RQ & Construct & Question & Source \\
\hline RQ3 & $\begin{array}{c}\text { Perception of } \\
\text { learning community }\end{array}$ & $\begin{array}{l}\text { Please indicate your agreement degree with following statements about your } \\
\text { study support. (5-likert scale) } \\
\text { I felt part of a group of students and teachers committed to learning. } \\
\text { I was able to explore academic interests with teachers and students. } \\
\text { I learned to explore ideas confidently with other students. } \\
\text { Students' ideas and suggestions were used during the classes. } \\
\text { I felt I belonged to the school community. }\end{array}$ & [13] \\
\hline RQ4 & $\begin{array}{l}\text { Perception of } \\
\text { student support }\end{array}$ & $\begin{array}{l}\text { Please indicate your agreement degree with following statements about your } \\
\text { study support. (5-likert scale) } \\
\text { The library services were readily accessible. } \\
\text { I was able to access IT (such as Chromebook/iPad) resources when I } \\
\text { needed them. } \\
\text { I was satisfied with the course and career advice provided. } \\
\text { Health, social worker, and psychological counselling services met my } \\
\text { requirements. } \\
\text { Relevant learning resources (eTextbook, database, software) were accessible } \\
\text { when I needed them. }\end{array}$ & [13] \\
\hline RQ5 & $\begin{array}{c}\text { Benefits / challenges/ } \\
\text { barriers of remote } \\
\text { learning }\end{array}$ & $\begin{array}{l}\text { For my remote learning, I am satisfied with ... (5-likert scale) } \\
\text { Convenience in studying. } \\
\text { Access of information and learning material. } \\
\text { Opportunities to interact with teachers. } \\
\text { Opportunities to interact with classmates. } \\
\text { What are your learning hindrances with remote learning? (checkbox) } \\
\text { Inadequate opportunity to study with other classmates. } \\
\text { Inadequate opportunity to discuss with teachers. } \\
\text { Inadequate opportunity to establish peer support. } \\
\text { Not confident enough to handle difficult task with online learning mode. } \\
\text { Difficult to apply concepts taught in the subject }\end{array}$ & [10] \\
\hline
\end{tabular}

\subsection{Data Analysis}

First, descriptive analysis (count and percentage) of demographic information were conducted. Second, reliability analysis was reported for all survey constructs. Third, descriptive analysis (mean and percentage) on survey response was conducted for each corresponding research question. Finally, to understand whether students' grade (freshman, sophomore, junior, senior), gender, ethnicity, family income, learning mode, and learning location have impacts on their learning experience, inferential analyses of ANOVA were conducted.

\section{Results}

In the following, the demographic results and reliability results of all survey constructs will be reported first. Then, survey results corresponding to five research questions, are presented. To understand the impacts of demographic variables on their learning experience, inferential analyses were conducted.

\subsection{Demographic Results}

Table 2 showed the result of demographic information with 62 respondents. First, the majority of our participants were seniors $(53 \%)$ and juniors $(23 \%)$. Second, more male $(60 \%)$ than female $(39 \%)$ participated in the study. Third, the family income of majority participants $(63 \%)$ were towards the lower end (under $\$ 50,000)$, while $28 \%$ were middle-income $(\$ 50,001-\$ 100,000)$ and $10 \%$ were high-income $(\$ 100,001-\$ 200,000)$. Fourth, surprisingly, Asian (66\%) and White (23\%) made up the majority of our sample. Fifth, in terms of learning mode, almost half of the participants chose remote learning (45\%), followed by in-person (36\%), and hybrid learning $(19 \%)$. Finally, in terms of learning 
location, most of the participants (52\%) prefer studying from home, 37\% prefer staying on campus, and the rest (11\%) prefer staying off-campus with friends.

Table 2. Results of Demographic Information.

\begin{tabular}{cccc}
\hline Measure & Item & Count & Percentage \\
\hline \multirow{3}{*}{ College Year } & Freshman & 4 & $6 \%$ \\
& Sophomore & 11 & $18 \%$ \\
& Junior & 14 & $23 \%$ \\
Gender & Senior & 33 & $53 \%$ \\
& Male & 37 & $60 \%$ \\
& Female & 24 & $39 \%$ \\
& Prefer not to say & 1 & $1 \%$ \\
Annual Income & less than $\$ 25,000$ & 21 & $34 \%$ \\
& $\$ 25,001-\$ 50,000$ & 18 & $29 \%$ \\
& $\$ 50,001-\$ 75,000$ & 9 & $15 \%$ \\
& $\$ 75,001-\$ 100,000$ & 8 & $13 \%$ \\
& $\$ 100,001-\$ 150,000$ & 5 & $8 \%$ \\
& $\$ 150,001-\$ 200,000$ & 1 & $1 \%$ \\
Ethnicity & African American & 3 & $5 \%$ \\
& Asian & 41 & $66 \%$ \\
& Hispanic & 4 & $6 \%$ \\
& White & 14 & $23 \%$ \\
& In-person & 22 & $36 \%$ \\
& hybrid & 12 & $19 \%$ \\
& remote & 28 & $45 \%$ \\
& On Campus & 23 & $37 \%$ \\
& Off Campus & 7 & $11 \%$ \\
& Home & 32 & $52 \%$ \\
\hline
\end{tabular}

\subsection{Reliability Results}

First, the reliability tests of five survey constructs were conducted. All five constructs reached an acceptable reliability (Cronbach's Alpha $>0.70$ ). Then the mean and standard deviation of each construct were reported in Table 3.

Table 3. Cronbach's Alpha, Mean, and Std Deviation of Five Survey Constructs.

\begin{tabular}{cccc}
\hline Construct & Cronbach's Alpha & Mean & Std. Deviation \\
\hline Learning Process & 0.73 & 4.11 & 0.62 \\
Mental Health & 0.86 & 3.10 & 0.67 \\
Learning Community & 0.83 & 3.92 & 0.72 \\
Student Support & 0.78 & 3.95 & 0.72 \\
Satisfaction & 0.72 & 3.96 & 0.71 \\
\hline
\end{tabular}

\subsection{Survey Results}

In the following, the aggregated results corresponding to above five research questions were presented in terms of college students' overall learning experience, mental health, perception of the learning community, perception of student support, and benefits and challenges/barriers.

On the Overall Learning Experience scale, the higher the response values are, the more positive students' overall learning process are. As shown on Figure 1, the average scores of all five questions were at a high level (around 3.98-4.19 on the 5-likert scale), which indicated an overall positive learning process. In particular, top three items were: the face-to-face resource sessions were valuable when supplemented with online learning (mean $=4.19)$; the student was able to work through the subject materials at their own paces (mean $=4.16)$; the student was encouraged to take responsibility for their own learning $($ mean $=4.15)$. 


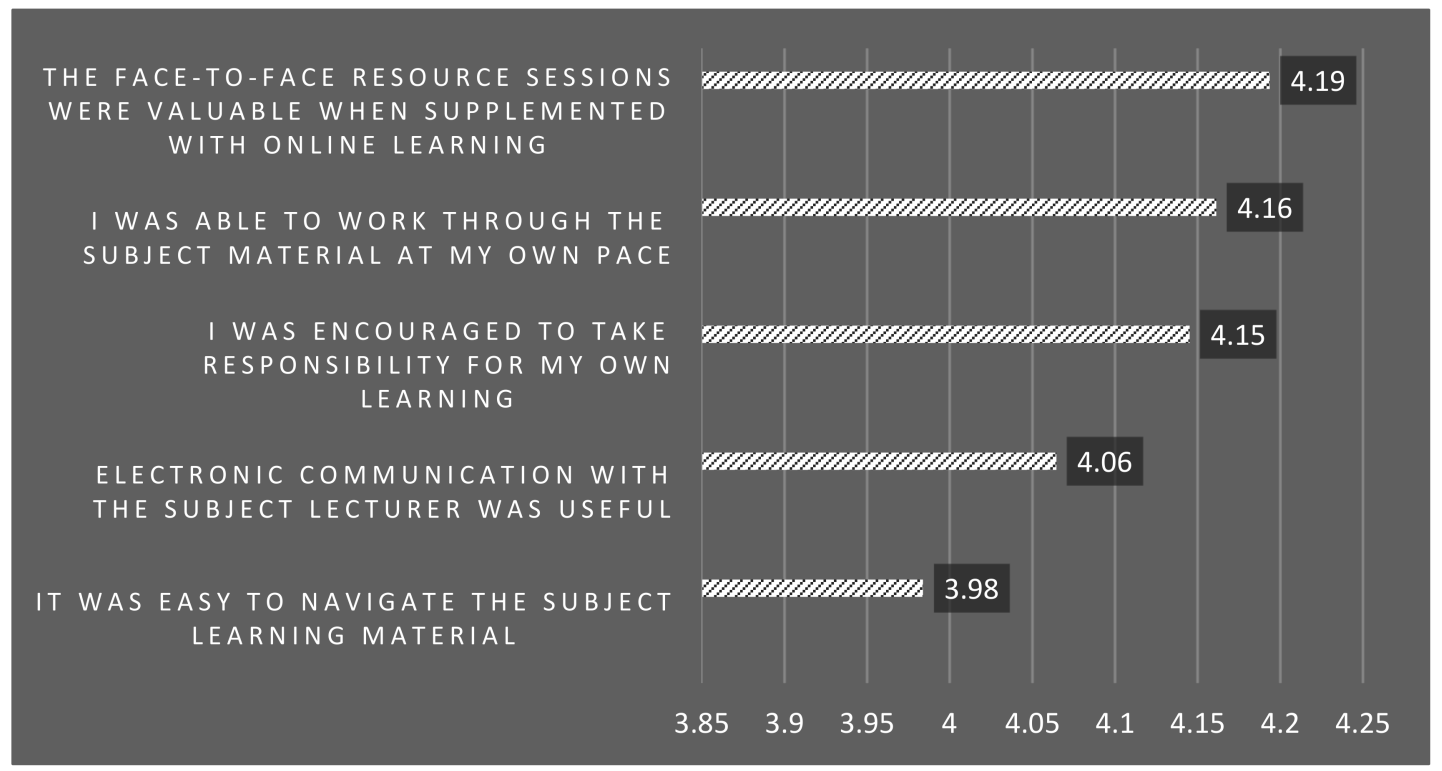

Figure 1. Result of Overall Learning Experience ( 1 = strongly disagree, 5 = strongly agree).

On the anxiety scale of GAD-7, the higher the response values are, the higher levels of mental problems are. As shown on Figure 2, the average scores of all seven questions were in low level (1.21-1.37 on 4-likert scale). A summered score (ranging 0-21) of 10 or greater represents a reasonable cut point for identifying cases of anxiety [5]. In our data, 55\% of respondents demonstrated anxiety (Table 4).

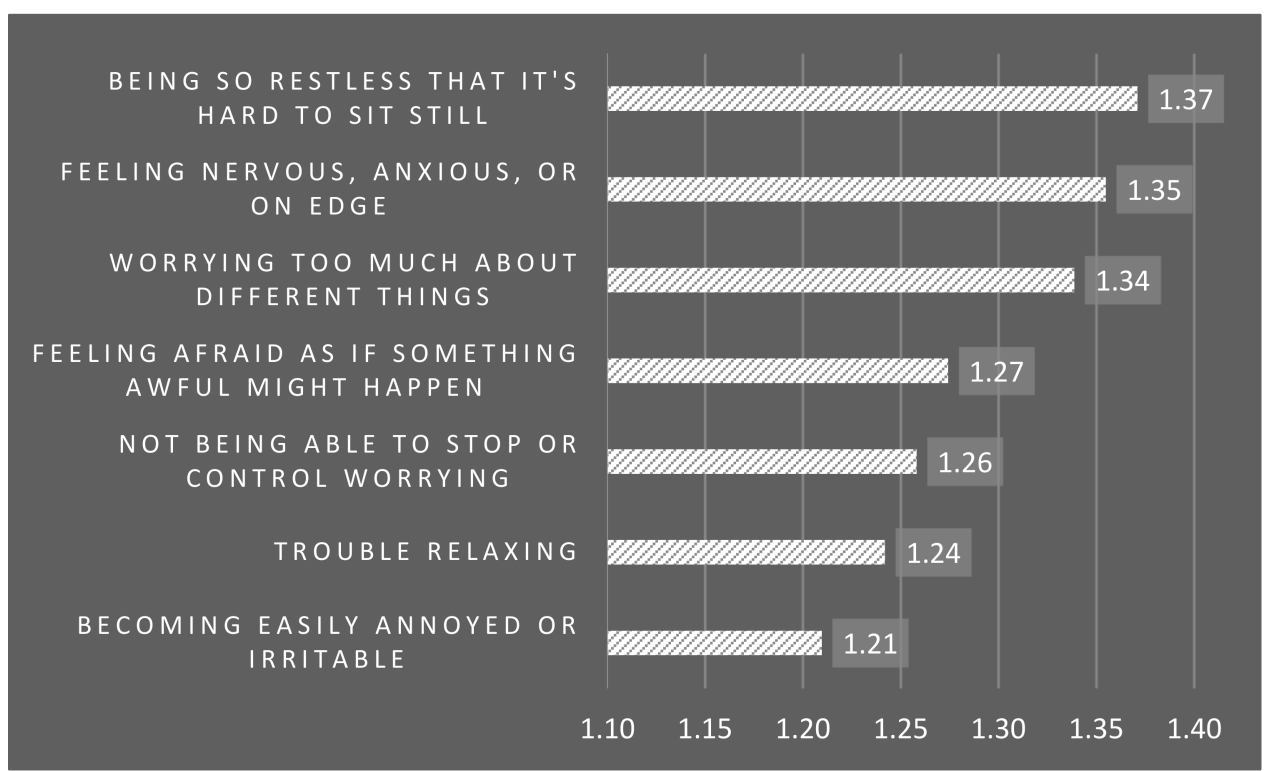

Figure 2. Result of Mental Health (GAD-7) $(0=$ Not at all, $1=$ Several days, $2=$ More than half the days, $3=$ Nearly every day).

Table 4. Anxiety Score and Percentage.

\begin{tabular}{ccc}
\hline Anxiety Score & Count & Percentage \\
\hline $0-9$ & 28 & $45 \%$ \\
$\geq 10 *$ & 34 & $55 \%$ \\
Total & 62 & $100 \%$ \\
\hline * Note: Anxiety score $\geq 10$ indicates anxiety (average $=8.05$, std $=6.10)$
\end{tabular}

${ }^{*}$ Note: Anxiety score $\geq 10$ indicates anxiety (average $=8.05$, std $=6.10$ ). 
On the depression scale of WHO-5, the higher the response values are, the better mental conditions are. As shown on Figure 3, the average scores of all five questions were in mid-to-high level (3.11-3.40 out of 6-likert scale), which indicated that the participants were inclined to a good mental health condition.

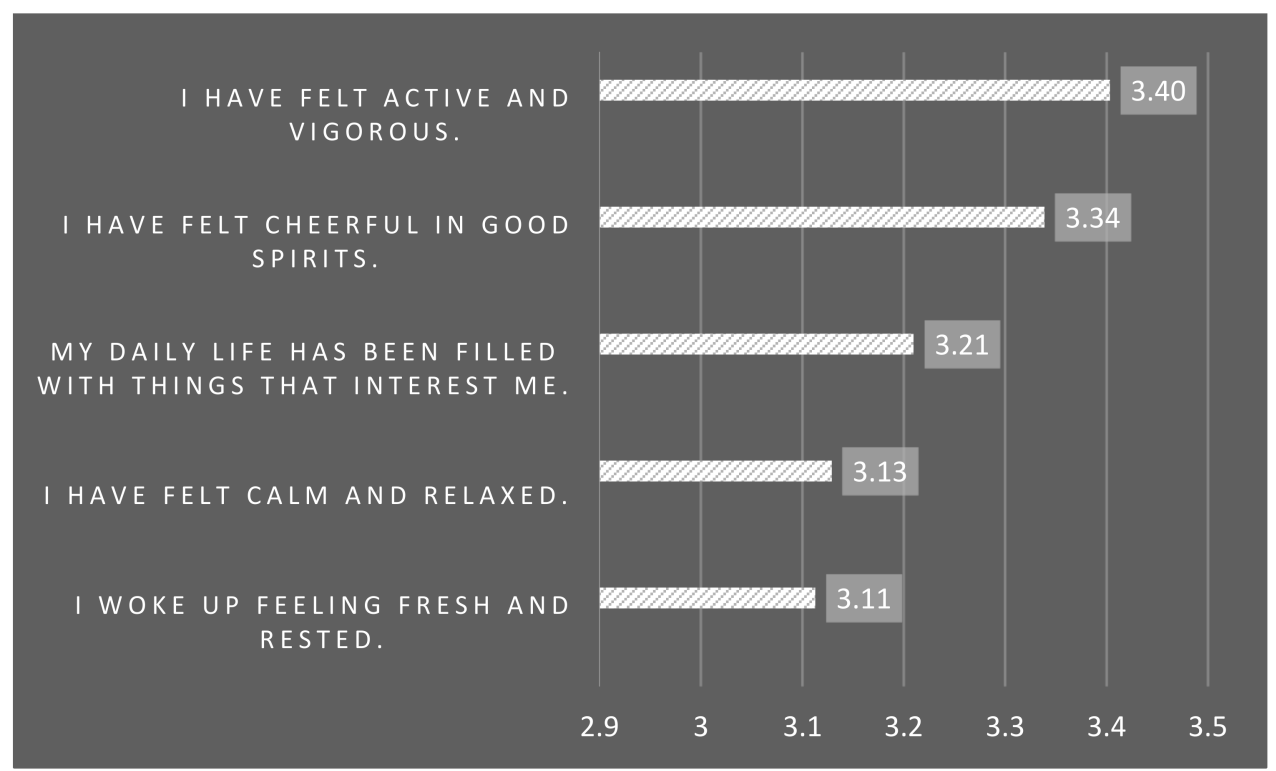

Figure 3. Result of Mental Health (WHO-5) $(0=$ No time, $1=$ Some of the time, $2=$ Less than half of the time, $3=$ More than half of the time, $4=$ Most of the time, $5=$ All the time).

A summed score (ranging 0-25) below 13 indicates depression [5]. In our data, only $37 \%$ of respondents demonstrated depression, while the majority of respondents were free of depression (Table 5).

Table 5. Depression Score and Percentage.

\begin{tabular}{ccc}
\hline Depression Score & Count & Percentage \\
\hline$\leq 13^{*}$ & 23 & $37 \%$ \\
$14-25$ & 39 & $63 \%$ \\
Total & 62 & $100 \%$ \\
\hline
\end{tabular}

* Note: Depression score $\leq 13$, indicates depression (average $=15.19$, std $=5.91$ ).

Overall, no depression was present in our data. A large percentage (63\%) of participants showed lower levels of depression than the cutoff value, and the average depression score indicated no depression. However, more than half (55\%) of our participants demonstrated higher level of anxiety than the cutoff value, even though the average anxiety score indicated no anxiety.

On the Learning Community scale, the higher the response values, the better the feeling toward the learning community. As shown on Figure 4, the average scores of all above five questions were in high level (3.79-3.98 on 5-likert scale), which indicated that the participants were feeling well with their learning community. 


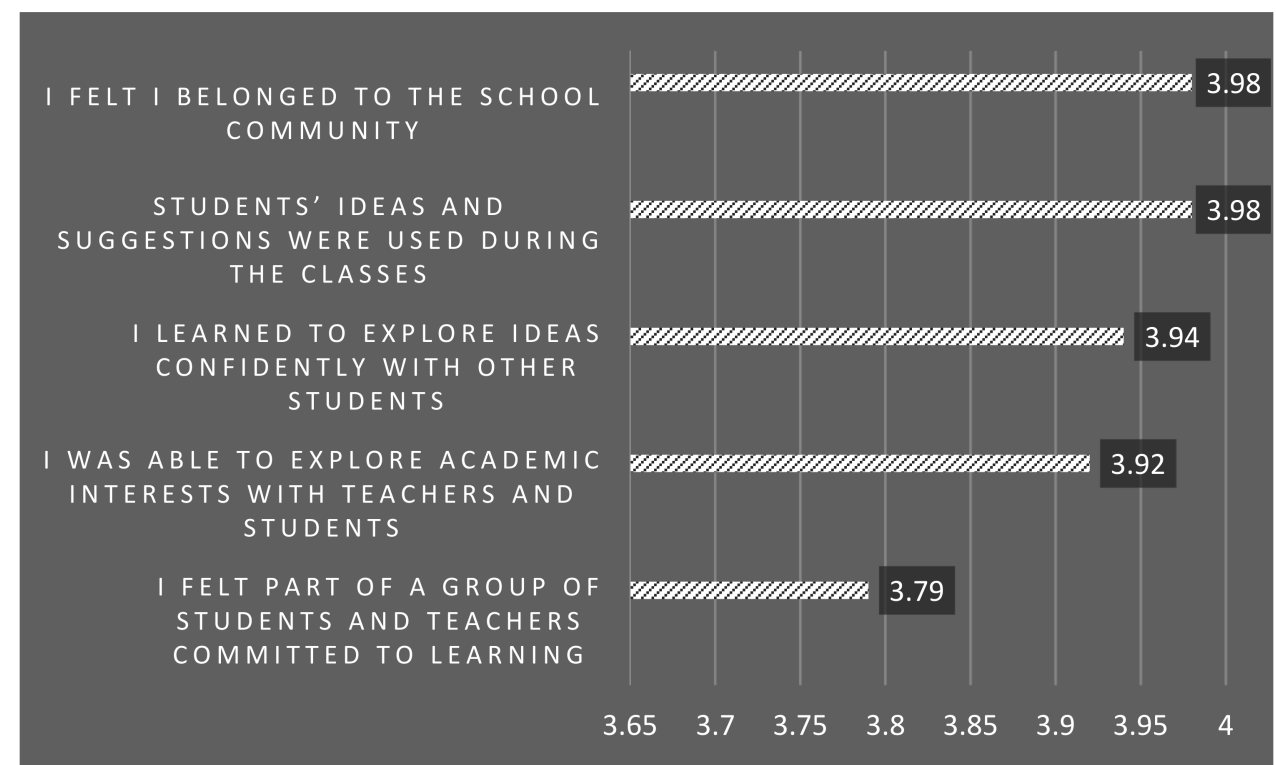

Figure 4. Result of Perceived Learning Community ( $1=$ Strongly Disagree, $5=$ Strongly Agree $)$.

On the Student Support scale, the higher the response values are, the better student support are perceived. As shown on Figure 5, the average scores of all five questions were in high level (3.76-4.11 on 5-likert scale), which indicated that the respondents perceived sufficient student support.

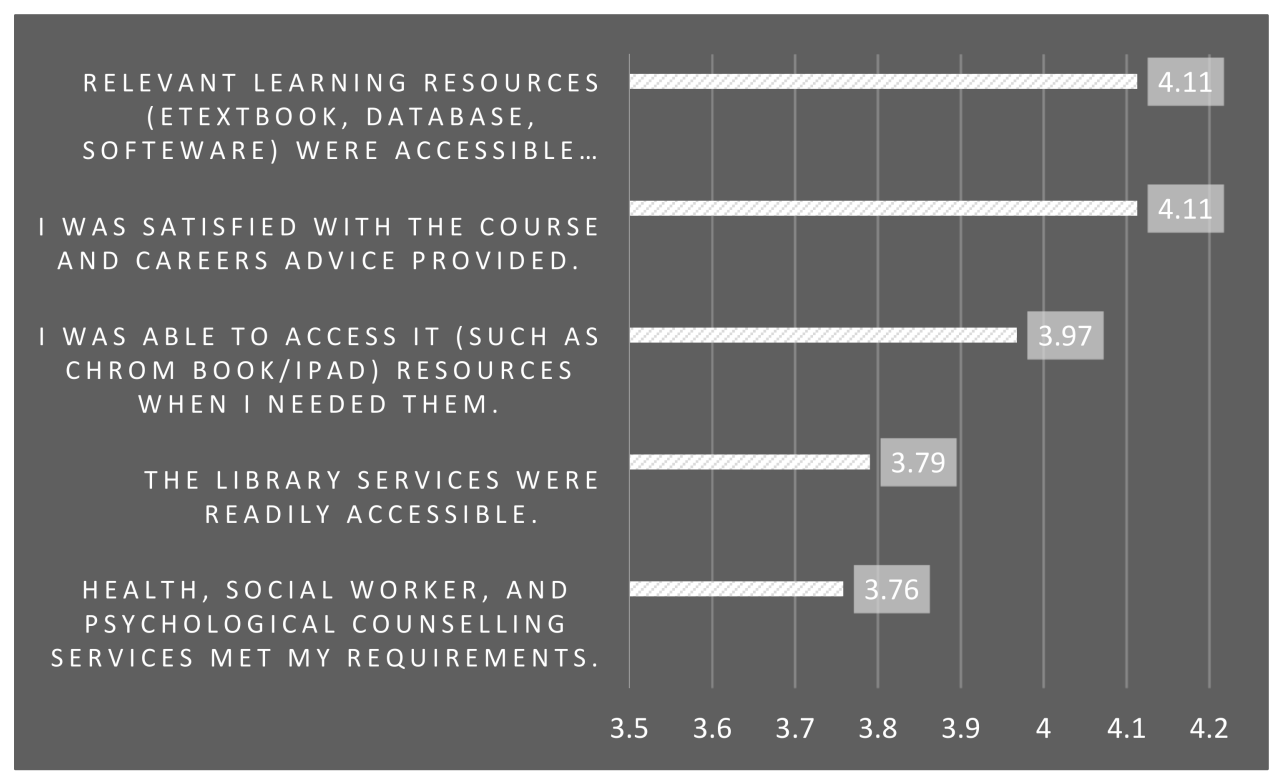

Figure 5. Result of Student Support ( 1 = Strongly Disagree, 5 = Strongly Agree).

On the Satisfaction scale, the higher the response values are, the higher level of students' satisfaction are. As shown on Figure 6, the average scores of all above five questions were in high level (3.73-4.15 on 5-likert scale), which indicated that the participants were satisfied with their learning experience. 


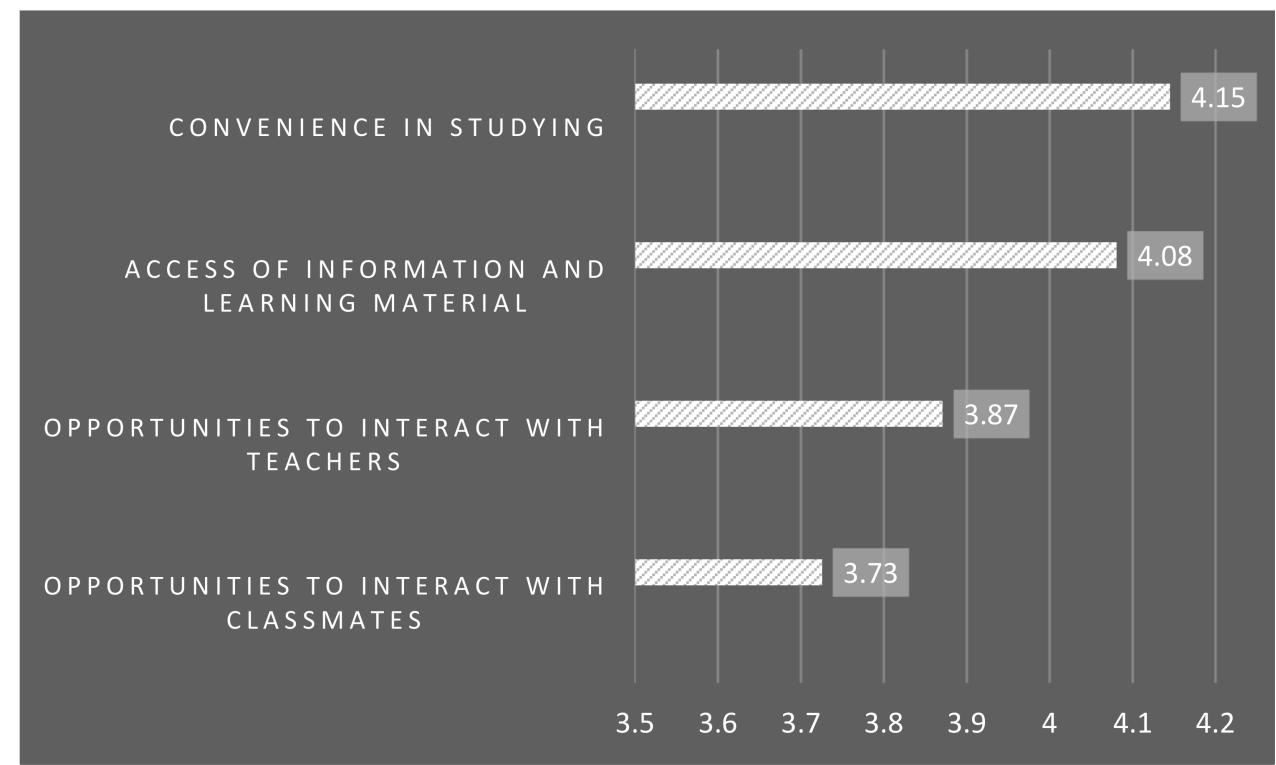

Figure 6. Result of Satisfaction ( 1 = Strongly Disagree, 5 = Strongly Agree).

This scale was a checkbox question. Figure 7 showed that online learning challenges students encountered included: inadequate opportunities to discuss with teachers (56\%), lack of opportunities to study with their classmates $(40 \%)$, inadequate opportunity for peer support (39\%), difficulty to apply concepts taught in the subject $(27 \%)$, and lack of confidence in handling difficult task with online learning mode $(13 \%)$.

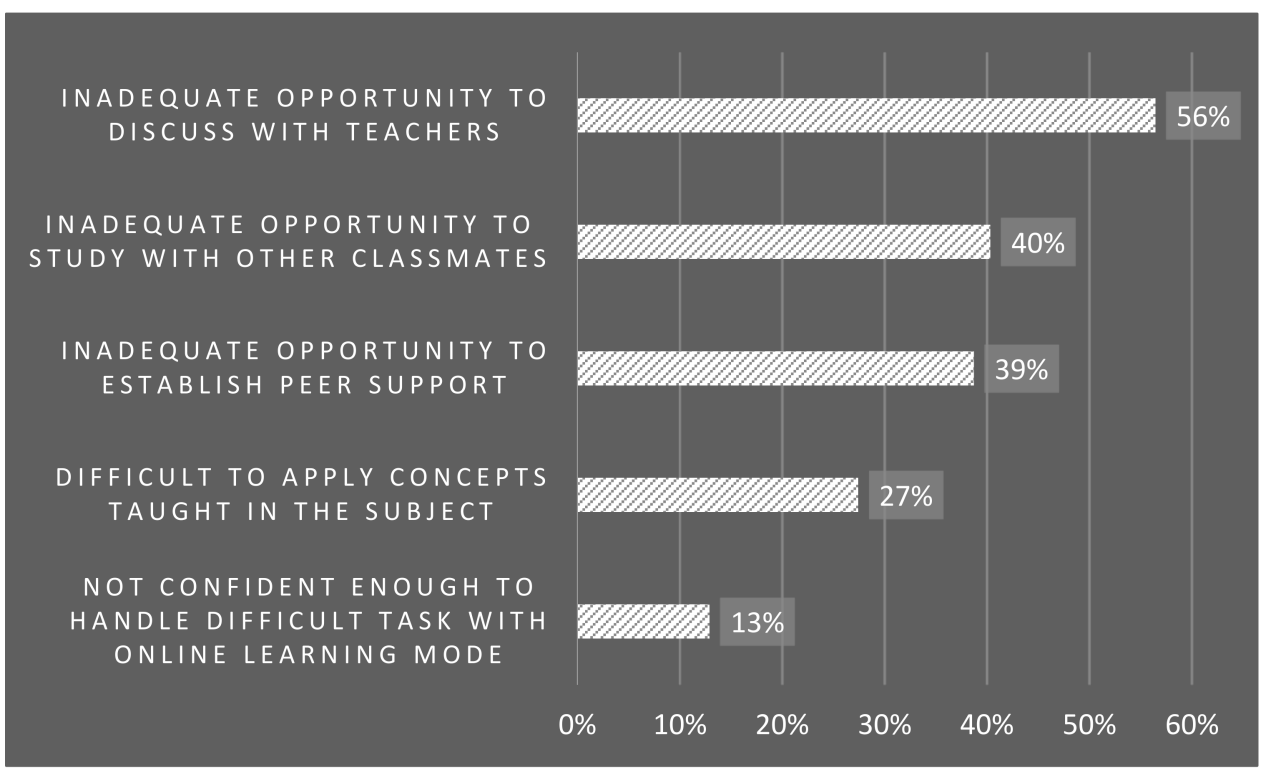

Figure 7. Result of Online Learning Hindrance (percentage).

\subsection{Inferential Analysis Results}

To understand whether students' grade (freshman, sophomore, junior, senior), gender, ethnicity, family income, learning mode, and learning location have impacts on their learning experience, inferential analyses of ANOVA have been conducted.

Results showed that no main effects of grade, gender, and ethnicity on all five survey constructs: learning process, mental health, learning community, student support, and satisfaction $(p>0.05)$. However, family income, learning mode, and learning location demonstrated significant effects. 
First, the main effect of family income was significant on the perception of the learning community $(\mathrm{F}(4,56)=3.01, p<0.05)$. Students from high-income group $(75 \mathrm{k}-100 \mathrm{k})$ (mean $=3.30$, std $=0.62$ ) perceived significantly worse about the learning community than students from low-income groups $(<25 \mathrm{k}$ : mean $=4.10$, std $=0.66 ; 25 \mathrm{k}-50 \mathrm{k}$ : mean $=4.11$, std $=0.63)$.

Second, the main effect of learning mode was significant for anxiety $(\mathrm{F}(2,59)=9.81$, $p<0.01)$, but no significant differences for depression $(p>0.05)$. Anxiety was highest for the learning mode of in-person (mean $=12.55$, std $=4.74)$, followed by remote $($ mean $=8.39$, std $=5.89$ ), and hybrid (mean $=4.17$, std $=5.18$ ). Posthoc Tukey of all three pairs comparisons were significant $(p<0.05)$.

Third, similar to the result of learning mode, the main effect of learning location was significant for anxiety $(\mathrm{F}(2,59)=3.44, p<0.05)$, but no significant differences for depression $(p>0.05)$. Posthoc Tukey of anxiety comparison showed that the on-campus group $($ mean $=11.52$, std $=5.46)$ showed significantly higher levels of anxiety than the home group $($ mean $=7.31$, std $=6.10)(p<0.05)$. The off-campus group (mean $=8.86$, std $=6.12$ ) showed no differences between both on-campus and home groups.

In addition, the main effect of learning location was significant on the perception of student support $(\mathrm{F}(2,59)=3.02, p=0.06)$. Posthoc Tukey showed that the on-campus group (mean $=4.01$, std $=0.44)$ perceived higher levels of student support than the off-campus group $($ mean $=3.37$, std $=1.07)(p<0.05)$.

\section{Discussion}

Our results provided rich information to the proposed research questions. Students' overall learning experience was found to be positive in this study. Students were in a good health condition in general. There was no presence of depression in our data, even though more than half of the students demonstrated anxiety. In addition, students felt that they belonged to their learning community. The students' support was found to be strong and adequate, and most of them were satisfied with their remote learning in COVID-19. Major benefits students perceived, related to remote learning, were the convenience to use online learning methods, and the easy accessibility to learning materials.

In the following, four major themes identified from our results will be discussed.

\subsection{Socioeconomic Impact on Learning Community}

Our inferential analysis showed that there were no main effects of grade, gender, ethnicity, and learning mode on five survey constructs. However, family annual income had a significant impact on a student's perception of the learning community. It is interesting that the students from low income families perceived more belonging to the learning community than those from high income families. This might be due to the likelihood that the students from low-income families received less restriction from their parents, so they were able to contact their friends in-person, while the students from high income families were more strictly prohibited to have face-to-face contact with their friends during COVID19. Although the in-person interaction during COVID-19 did not necessarily benefit these students' physical health, it probably helped them to have better participation in their learning community in comparison to those high-income students who were constrained at home.

\subsection{Optimal Learning Location and Learning Mode}

Our results revealed that the learning location has an impact on students' learning experience. Specifically, the students who chose to study on-campus perceived better student support than those who were off-campus with friends. It is understandable that both academic resources (such as lab materials, abundant library in-print collection), technical resources (such as stable campus network, site accessible software, high-end computers), as well as other services (such as health, psychological counseling, career service events) are more accessible on-campus than off-campus. Surprisingly, the impact of 
learning location on mental health was opposite to our prediction. Initially, we assumed that students at home might feel isolated from their peers, thus exhibiting a higher level of anxiety than on-campus students. However, students in the on-campus group, in fact, showed higher levels of anxiety than the home group. A possible explanation is oncampus students, at the time, had to follow very strict social distancing and other related policies. There were many ambiguities in those evolving policies. Students constantly worried that they may be deported home if they violated those strict rules. Therefore on-campus students actually showed much a higher level of anxiety than home students. The off-campus group student stayed with their friends while taking courses online. It was considered the best choice at the time. However, the small sample size of that condition in our data did not allow us to draw any conclusive statements here. A future study with bigger sample size of this condition is warranted.

In addition, our results showed that the learning mode has an impact on students mental health. In particular, hybrid students had the lowest anxiety level, and in-person students had the highest anxiety level. Remote students had a level of anxiety between in-person and remote students. The high level of anxiety from the in-person student group might be due to the likelihood that students were afraid of in-person infection of COVID-19. The first vaccine shots were given on 14 December 2021 in the U.S. When we collected data for this study in January 2021, only a very small portion of frontline workers and health care workers were vaccinated. The majority of college students were unvaccinated at that time. Although these in-person students got better support in learning, the peak of COVID-19 infection right after Christmas and New Year holidays in the U.S. might make them fear the possible virus spread out in-person. Remote learning was the safest learning mode in terms of possible COVID-19 infection. They did not have to worry about getting infected and social distancing. However, it lacks in-person interaction and social support. Therefore, the hybrid group was shown as the optimal learning mode in our study. On the one hand, the hybrid students got sufficient student support from the campus interactions. On the other hand, they did not have to worry much about keeping social distancing and infection too much, so they presented the lowest anxiety level.

\subsection{Improved Mental Health}

Studies similar to ours were conducted last year at the beginning of COVID-19. Compared to their findings $[5,6,24]$, college students showed improved mental health in our study. In the spring 2020, when many universities in the U.S. closed their campuses due to the emergency of COVID-19, they were unprepared for the sudden shift to online teaching and learning. The campus network infrastructure was weak for heavy use, the grading policy had not yet been revised to adapt the new learning method, and psychological and material support to students were inadequate [7]. College students worried about the efficiency of remote learning [11]. Students reported negative impacts of remote learning on their mental health including high levels of stress, anxiety, and depression [5,6,24]. However, one year after the outbreak of COVID-19, the college students demonstrated positive overall learning experience, improved mental health, high levels of satisfaction, and student support in our study. The prevalence of depression dropped from $48.3 \%$ [5] to $37 \%$. This positive shift is a good indication of students' successful adaption to remote learning as well as an overall improvement in university responses to COVID-19. Nevertheless, 55\% of students still had prevalence of anxiety in our study. Thus, this evidenced that infectious diseases like COVID-19 may have an immense influence on youth mental health. While students coped with their depression pretty well, universities should continue to develop effective interventions for their anxiety. With the wide vaccine implementation on the way, we expect that students' anxiety will significantly drop in the future. 


\subsection{Overall Positve Learning Experience}

As shown in the Results section (Figures 1 and 4-6), students in our study reported an overall positive learning experience, including high perception of learning community, sufficient student support, and high level of satisfaction with their learning experience.

This finding is consistent with other similar studies. In Gonzalez et al. [25], they reported a significant positive effect of the COVID-19 confinement on students' performance in Spain. They found that students adapted their learning strategies to a more continuous habit during COVID-19, and led to an improved learning efficiency, and better grades (improved learning performance). In another study at Pakistan [26], a positive relationship between technology acceptance and eLearning during COVID-19 was reported. An increased online learning adaptation was due to broader options to learn new things, which was provided by online technologies for both students and teachers.

\subsection{Barriers for Online Learning}

Despite that the students were satisfied with their communication with classmates and teachers, most students reported the inadequate opportunities to interact with both teachers and peers was still the major challenge and barrier to their online learning. Another challenge and barrier were the lack of confidence in dealing with difficult tasks in online learning, in which the weak network infrastructure and lack of equipment (such as iPad or laptop) were, in particular, out of the student's control.

The inadequate interaction problem in online learning is not new. In fact, a similar study [9] on online learning before COVID-19 showed similar findings. In that study, students who were unfamiliar with the online learning environment rejected using it as their study method. Four factors were identified for barriers to online learning: lack of faceto-face interaction, inadequate opportunity of real-time group discussion, low-efficiency, and causing anxiety [9]. Due to the innovative online learning technology and policy, the efficiency had been improved, and only $13 \%$ of students in our study felt uncomfortable to handle tasks with an online learning method. However, the inadequate interaction problem still remains. It is found, in our study, that $40 \%$ and $56 \%$ of the participants felt the lack of interaction between classmate and teacher, respectively. In fact, the inaccessible interaction of online learning mode is one of the major shortcomings that should be improved in the future.

\section{Conclusions}

In summary, our study found that students' learning experience during COVID-19 was positive. They were in a fair mental health condition. Students reported good belonging to their learning community and sufficient student support. Most students were satisfied with remote learning, and no serious barriers were found except inadequate interactions between students and teachers, and between students.

In terms of college student's mental health, the hybrid model was shown to be the optimum learning option even one year after the outbreak of infectious COVID-19. It suggested that the colleges should consider encouraging hybrid learning, instead of other learning options, when on-site safety was not ensured. On-campus in-person learning is not always the best learning mode, as the majority of us thought.

\subsection{Limitation}

Due to the quarantine situation, we were unable to access students from campuses. Alternatively, we recruited our participants on an online survey platform. Even after several rounds of posting and reposting, the sample reached a saturation, in which the same participants responded to our solicitation. We were not able to grow our sample size as we liked. In addition, the variety of racial groups was limited with most participants being Asians (66\%) and white (23\%). 


\subsection{Future Research}

In pursuit of more precise and reliable results, a larger sample size, and a broader racial group, is crucial in future research. Comparison between private and public colleges, small liberal art colleges, and comprehensive universities will expand our findings to a broader context, and different coping strategies might be identified for different settings. Finally, with wide implementation of COVID-19 vaccines and their effectiveness in coping with the disease, we expect great improvements in college students' mental health and learning experience in the near future.

Author Contributions: Conceptualization, Q.Z.; Data curation, J.Z. and Q.Z.; Formal analysis, J.Z. and Q.Z.; Investigation, J.Z. and Q.Z.; Methodology, J.Z. and Q.Z.; Project administration, Q.Z.; Resources, Q.Z.; Supervision, Q.Z.; Validation, Q.Z.; Writing—original draft, J.Z.; Writing—review \& editing, J.Z. and Q.Z. Both authors have read and agreed to the published version of the manuscript.

Funding: This research received no external funding.

Institutional Review Board Statement: The study was approved by the Institutional Review Board of Long Island University (protocol code 21/01-001 and date of approval: 4 January 2021).

Informed Consent Statement: Informed consent was obtained from all subjects involved in the study.

Conflicts of Interest: The authors declare no conflict of interest.

\section{References}

1. Velavan, T.P.; Meyer, C.G. The COVID-19 epidemic. Trop. Med. Int. Health 2020, 25, 278. [CrossRef] [PubMed]

2. Jiménez-Pavón, D.; Carbonell-Baeza, A.; Lavie, C.J. Physical exercise as therapy to fight against the mental and physical consequences of COVID-19 quarantine: Special focus in older people. Prog. Cardiovasc. Dis. 2020, 63, 386. [CrossRef] [PubMed]

3. Van Lancker, W.; Parolin, Z. COVID-19, school closures, and child poverty: A social crisis in the making. Lancet Public Health 2020, 5, e243-e244. [CrossRef]

4. Moldavan, A.M. Using Digital Education Amid a Global Pandemic to Address Coursework and Wellbeing. Digital Culture and Education. Available online: https:/ / www.digitalcultureandeducation.com/reflections-on-covid19/coursework-and-wellbeing (accessed on 19 May 2021).

5. Gao, J.; Zheng, P.; Jia, Y.; Chen, H.; Mao, Y.; Chen, S.; Wang, Y.; Fu, H.; Dai, J. Mental health problems and social media exposure during COVID-19 outbreak. PLoS ONE 2020, 15, e0231924.

6. $\quad$ Liang, L.; Ren, H.; Cao, R.; Hu, Y.; Qin, Z.; Li, C.; Mei, S. The effect of COVID-19 on youth mental health. Psychiatr. Q. 2020, 91, 841-852. [CrossRef] [PubMed]

7. Reich, J.; Buttimer, C.J.; Fang, A.; Hillaire, G.; Hirsch, K.; Larke, L.R.; Littenberg-Tobias, J.; Madoff Moussapour, R.; Napier, A.; Thompson, M.; et al. Remote Learning Guidance from State Education Agencies During the Covid-19 Pandemic: A First Look. 2020. Available online: https:/ / doi.org/10.35542/osf.io/437e2 (accessed on 2 April 2020).

8. Zhang, W.; Wang, Y.; Yang, L.; Wang, C. Suspending classes without stopping learning: China's education emergency management policy in the COVID-19 Outbreak. J. Risk Financ. Manag. 2020, 13, 55. [CrossRef]

9. Chang, R.I.; Hung, Y.H.; Lin, C.F. Survey of learning experiences and influence of learning style preferences on user intentions regarding MOOCs. Br. J. Educ. Technol. 2015, 46, 528-541. [CrossRef]

10. Sit, J.W.; Chung, J.W.; Chow, M.C.; Wong, T.K. Experiences of online learning: Students' perspective. Nurse Educ. Today 2005, 25, 140-147. [CrossRef]

11. Nenko, Y.; Kybalna, N.; Snisarenko, Y. The COVID-19 Distance Learning: Insight from Ukrainian students. Revista Brasileira de Educação do Campo 2020, 5, e8925. [CrossRef]

12. Ramsden, P. A performance indicator of teaching quality in higher education: The Course Experience Questionnaire. Stud. High Educ. 1991, 16, 129-150. [CrossRef]

13. McInnis, C.; Griffin, P.; James, R.; Coates, H. Development of the Course Experience Questionnaire (CEQ); Department of Education, Training and Youth Affairs: Canberra, Australia, 2001.

14. Grace, D.; Weaven, S.; Bodey, K.; Ross, M.; Weaven, K. Putting student evaluations into perspective: The course experience quality and satisfaction model (CEQS). Stud. Educ. Eval. 2012, 38, 35-43. [CrossRef]

15. Pintrich, P.R.; Smith, D.A.; Garcia, T.; McKeachie, W.J. Reliability and predictive validity of the Motivated Strategies for Learning Questionnaire (MSLQ). Educ. Psychol. Meas. 1993, 53, 801-813. [CrossRef]

16. Pintrich, P.R.; de Groot, E.V. Motivated Strategies for Learning Questionnaire [Database record]. PsycTESTS 1990. [CrossRef]

17. Meijs, C.; Neroni, J.; Gijselaers, H.J.M.; Leontjevas, R.; Kirschner, P.A.; de Groot, R.H.M. Motivated Strategies for Learning Questionnaire, Part B-Distance Education [Database record]. PsycTESTS 2019. [CrossRef] 
18. Pekrun, R.; Goetz, T.; Frenzel, A.C.; Barchfeld, P.; Perry, R.P. Measuring emotions in students' learning and performance: The Achievement Emotions Questionnaire (AEQ). Contemp. Educ. Psychol. 2011, 36, 36-48. [CrossRef]

19. Leung, C.C.; Lam, T.H.; Cheng, K.K. Mass masking in the COVID-19 epidemic: People need guidance. Lancet 2020, $395,945$. [CrossRef]

20. Pellegrini, M.; Ponzo, V.; Rosato, R.; Scumaci, E.; Goitre, I.; Benso, A.; Belcastro, S.; Crespi, C.; De Micheli, F.; Ghigo, E.; et al. Changes in weight and nutritional habits in adults with obesity during the "lockdown" period caused by the COVID-19 virus emergency. Nutrients 2020, 12, 2016. [CrossRef]

21. Nasu, V.H. Remote Learning Under COVID-19 Social Distancing: Discussion, Resources, Implications for Accounting Faculty and Students, and a Netnography Study. In Proceedings of the XX USP International Conference in Accounting, São Paulo, Brazil, 29-31 July 2020.

22. Cao, W.; Fang, Z.; Hou, G.; Han, M.; Xu, X.; Dong, J.; Zheng, J. The psychological impact of the COVID-19 epidemic on college students in China. Psychiatry Res. 2020, 287, 112934. [CrossRef]

23. Jahanshahi, A.A.; Dinani, M.M.; Madavani, A.N.; Li, J.; Zhang, S.X. The distress of Iranian adults during the Covid-19 pandemicMore distressed than the Chinese and with different predictors. Brain Behav. Immun. 2020, 87, 124-125. [CrossRef] [PubMed]

24. Brown, S.M.; Doom, J.R.; Lechuga-Peña, S.; Watamura, S.E.; Koppels, T. Stress and parenting during the global COVID-19 pandemic. Child Abus. Negl. 2020, 110, 104699. [CrossRef]

25. Gonzalez, T.; De La Rubia, M.A.; Hincz, K.P.; Comas-Lopez, M.; Subirats, L.; Fort, S.; Sacha, G.M. Influence of COVID-19 confinement on students' performance in higher education. PLoS ONE 2020, 15, e0239490. [CrossRef] [PubMed]

26. Alhumaid, K.; Ali, S.; Waheed, A.; Zahid, E.; Habes, M. COVID-19 \& Elearning: Perceptions \& Attitudes of Teachers Towards E-Learning Acceptancein The Developing Countries. Multicult. Educ. 2020, 6, 100-115. 